\title{
Immunotherapy and malignant pleural mesothelioma
}

\author{
Timothy Allen*, Nepton Sheikh- Khoni, Shoja E Razavi and Naveed Basha Court \\ Global Allied Pharmaceuticals, Center for Excellence in Research and Development, 160 Vista Oak Dr. Longwood, FL 32779, USA
}

\begin{abstract}
Malignant pleural mesothelioma is an aggressive type of cancer in which cancerous cells are found in the lining of the abdomen or chest that occurs due to asbestos exposure in the mesothelium. According to the National Cancer Institute's Surveillance, Epidemiology and End Results (SEER), there are around 2,500-3,000 new cases per year of malignant mesothelioma observed in the United States, mainly in elderly men. It occurs mainly in males as compared to females and the chances of risk increases with the age, but this cancer can emerge in both males and females at any age. It forms due to the neoplastic transformation of mesothelial cells and it is associated with the genetic changes and other phenotypic changes, which change cell-matrix and cell-cell interaction and regulation of cell death and cell proliferation. The targeted treatment is focused at a precise molecular target, which is very close to a hallmark of cancer. These targets should be assessable with a specific biomarkers and the measurement of these targets should be associated with different clinical outcome when these targeted treatment is administered. Malignant pleural mesothelioma is characterized via a composite genomic modification, through the defeat of chromosomal loci encoding for different tumor suppressor genes such as TP53, NF2, p14, and p16. These types of genomic changes are very ordinary but, unluckily, these are not appropriate to be targeted through the available drugs. Over the last decade, various targeted agents have been explored in malignant pleural mesothelioma, and in some of them; the preclinical rationale was very weak for exploring clinical activity. There are some drugs which consistently revealed their activity in malignant pleural mesothelioma, but these drugs are under clinical trials.
\end{abstract}

Abbreviations: ADCC: Antibody Dependent Cellular Cytotoxicity; ADC: Antibody-Drug Conjugate; CML: Chronic Myeloid Leukemia; CTA: Cancer Testis Antigens; CTL: Cytotoxic T-Lymphocyte; CTLA4: Cytotoxic T-Lymphocyte-Associated Protein-4; FAK: Focal Adhesion Kinase; G-CSF: Granulocyte Colony Stimulating Factor; GM-CSF: Granulocyte-Macrophage Colony Stimulating Factor; HCF: Hepatocyte Growth Factor; SF: Scatter Factor; IL: Interleukin; M-CSF: Macrophage Colony Stimulating Factor; MAPK: Mitogen-Activated Protein Kinase Kinase; MVA: Modified Vaccinia Ankara; NF: Nuclear Factor; PDGF: Platelet Derived Growth Factor; TAA: Tumor Associated Antigens; TGF-B: Transforming Growth Factor Beta; TSG Tumor Suppressor Gene; VEGF: Vascular Epidermal Growth Factor; WT-1: Wilms Tumor 1.

\section{Introduction}

Malignant pleural mesothelioma is a rare and aggressive type of cancer in which cancerous cells are found in the lining of the abdomen or chest. The contact to airborne asbestos particles enhances one's risk of rising malignant mesothelioma. The incidence of malignant pleural mesothelioma has risen since the mid- $20^{\text {th }}$ century worldwide [1]. Malignant pleural mesothelioma is one of the rarest causes of death worldwide [2]. According to the National Cancer Institute's Surveillance, Epidemiology and End Results (SEER), there are around 2,500-3,000 new cases per year of malignant mesothelioma observed in the United States, mainly in elderly men. WHO recorded 4.9 per million age-adjusted mortality rates between 1994 and 2008, a mean age of 70 years at death and there is a ratio of 3.6:1 between male and female [3]. It includes different types of histo pathologic and genetic characteristic [2]. In the year 2004, 15 per 1,000,000 incidences may have pointed in the United States.

Malignant pleural mesothelioma occurs mainly in males as compared to females and the chances of risk increases with the age, but this cancer can emerge in both males and females at any age. About one fifth to one third of all malignant pleural mesothelioma are peritoneal
[4] and its incidence rate is $0.2-2.0$ per million per year in female and 0.5-3.0 per million per year in males [3,4]. Median survival has been reported as 16 months for patients with malignant pleural disease and 5 months for patients with extensive disease. Etiological factors that contribute to the progression of the disease are exposure to asbestos and smoking [5,6].

\section{Etiology/predisposing factors}

Malignant pleural mesothelioma is a cancer which occurs due to asbestos exposure in the mesothelium. There are some other risk factors of malignant pleural mesothelioma, which includes smoking, exposure to dusts, radiation and chemicals such as carbon nanotubes, zeolite, radiation, erionite exposure, and simian virus 40 [6]. Age, histology, performance status, and stage are found to be as the most important prognostic factors [1].

\section{Pathophysiology/molecular basis}

Malignant pleural mesothelioma forms due to the neoplastic transformation of mesothelial cells and it is associated with the genetic

${ }^{*}$ Correspondence to: Timothy Allen, Global Allied Pharmaceuticals, Center for Excellence in Research and Development, 160 Vista Oak Dr. Longwood, FL 32779, USA, E-mail: timallenmed69@gmail.com

Key words: malignant pleural mesothelioma, mesothelial cells, sarcomatoid, epithelioid, and biphasic, tumor suppressor gene (tsg), $\beta$-catenin protein, platelet derived growth factor ( $p d g f)$, vascular epidermal growth factor (vegf) and hepatocyte growth factor/scatter factor ( $h \mathrm{gf} / \mathrm{sf}$ ), granulocyte colony stimulating factor ( $g$-csf), granulocyte-macrophage colony stimulating factor (gm-csf), interleukin (il)-6 or 8, macrophage colony stimulating factor ( $m$-csf), focal adhesion kinase (fak), platelet-derived growth factor receptor (pdgf) and cytokine tumor necrosis factor alpha (tnf-alpha)

Received: December 18, 2018; Accepted: January 11, 2019; Published: January 14, 2019 
changes and other phenotypic changes, which change cell-matrix and cell-cell interaction and regulation of cell death and cell proliferation. Usually, malignant pleural mesothelioma is categorized into three histological subtypes and that is sarcomatoid, epithelioid, and biphasic [7]. Currently, such data published on $\beta$-catenin protein have shown that this $\beta$-catenin protein may translocate to the nucleus and act as a co-activator of different transcription factors, such as LEF/TCF. Different molecular changes in tumor suppressor gene (TSG) are mentioned in Table- 1 that is involve in the occurrence of the malignant pleural mesothelioma (Table 1) [8].

The platelet derived growth factor (PDGF) acts as a regulatory factor in malignant pleural mesothelioma cell proliferation, which performed either directly or through the hyaluronan/CD44 pathway. Even all normal pleural mesothelial cells express lower levels of PDGF-A mRNA transcripts and other mesothelial cell show equally higher levels of both PDGF-A and PDGF-B chains. Both PDGF-A and PDGF-B receptors are differentially expressed, correspondingly. Insulin-like growth factor-1 (IGF-1) is also involved in the regulation of mesothelioma cell development. Malignant pleural mesothelioma cell produces mRNA transcripts for IGF-1, IGF-binding protein 1 or 3 , and the IGF-1 receptor. In some cases of mesothelioma, there are two growth factors: vascular epidermal growth factor (VEGF) and hepatocyte growth factor/scatter factor (HGF/SF), which may be engaged in an autocrine loop of proliferation, because mesothelioma cells indicated both these factors and their relevant receptors. There are different cytokines such as granulocyte colony stimulating factor (G-CSF), granulocyte-macrophage colony stimulating factor (GMCSF), interleukin (IL)-6 or 8, macrophage colony stimulating factor (M-CSF), and transforming growth factor beta (TGF-b) which are also expressed through human mesothelioma cells but their appropriate roles are yet to be determined in the pathogenesis of tumors. The transforming growth factor beta (TGF-b) may potentiate the development of mesothelioma cells, and antisense oligodeoxy nucleotides to other isoforms of TGF-b emerge to inhibit the development of tumors [12,13].

Note: aifferent methods are used in each and every study which is based on specificity/sensitivity rates, and mutations like homozygous deletion in FISH are different. Though, each study used different analytical techniques like single-strand conformation polymorphism analysis, sanger sequencing, PCR, and reverse transcriptase-PCR, western blot analysis, comparative genomic hybridization analysis, and next-generation sequencing.

${ }^{\mathbf{b}} \mathrm{HD}$, homozygous deletion.

'Data are presented as \% (number of positive/total cases).

${ }^{\mathrm{d} C O S M I C}$ Mutant Export version 64

${ }^{\mathrm{e} C e l l}$ line data.

\section{Hallmarks of cancer comprise modulating factors and biological capabilities}

The targeted treatment is focused at a precise molecular target, which is very close to a hallmark of cancer. These targets should be assessable with a specific biomarkers and the measurement of these targets should be associated with different clinical outcome when these targeted treatment is administered. Recently, clinical guidelines don't suggest any biological or targeted therapy in malignant pleural mesothelioma. The development of cancer in humans is a very complex process with different steps. There are different factors which are involved in the growth of cancer and have been suggested as an important part to raise options for new treatment modalities. Hallmarks of cancer comprises of modulating factors and biological capabilities to produce an environment in which cancer cells can flourish (Figure 1) (Table 2) (Table 3) [15].

\section{Immunotherapy}

\section{Kinase Inhibitors}

Non-FDA Approved Kinase Inhibitors (Table 4)

\section{Monoclonal Antibody Drugs (MABs)}

Non-FDA Approved MAB Drugs (Table 5)

\section{Proteasome Inhibitors}

Non-FDA Approved Proteasome Inhibitors (Table 6)

\section{Vaccines}

Non-FDA Approved Vaccines (Table 7)

\section{Cytokine treatment}

NGR-hTNF: A cytokine-peptide conjugate composed of the cytokine tumor necrosis factor alpha (TNF-alpha) chemically linked to the peptide CNGRC. The peptide moiety CNGRC, a ligand for the membrane-bound metalloprotease CD13, binds to endothelial cells of the angiogenic vasculature that express CD13 (also known as aminopeptidase N); subsequently, the TNF-alpha moiety induces apoptosis in endothelial cells expressing CD13, thereby inhibiting tumor-associated angiogenesis (Table 8).

\section{Gene therapy}

TargomiRs: A nanoparticle-based formulation composed of a microRNA 16 (miR-16) mimic, a double-stranded, 23 base pair, synthetic RNA molecule, encapsulated in nonliving bacterial minicells and coated with anti-epidermal growth factor receptor (EGFR) antibodies, with potential antineoplastic activity. Upon intravenous administration and subsequent transfection, nanocell-encapsulated miR-16-based microRNA mimic targets EGFR-expressing tumor cells and facilitates

Table 1. Molecular changes in tumor suppressor gene (TSG) [9-11]

\begin{tabular}{|l|l|l|}
\hline Molecular changes & Cellular perturbation & Potential etiological factor \\
\hline $\begin{array}{l}\text { TP53: Inactivation. a) Low rate of } \\
\text { point mutation. } \\
\text { b) Binding to viral proteins }\end{array}$ & $\begin{array}{l}\text { Cell cycle control: inactivation of } \\
\text { checkpoints controlling apoptosis and cell } \\
\text { cycle progression after DNA damage. }\end{array}$ & $\begin{array}{l}\text { a) Asbestos: low rate of point mutations in the murine homologue Trp53 is establishing in } \\
\text { mesothelioma cells from asbestos-exposed mice. Loss of heterozygosity in mesothelioma cells from } \\
\text { mice, homozygous at the Trp53 locus, exposed to asbestos fibers. } \\
\text { b) SV40: binding to large T antigen in human mesothelioma. }\end{array}$ \\
\hline NF2: frequent inactivation. & $\begin{array}{l}\text { Destabilization of adherens junctions. Loss } \\
\text { of negative control of cell proliferation. }\end{array}$ & $\begin{array}{l}\text { Asbestos: recurrent loss of heterozygosity of N } f 2 \text { in mesothelioma cells from mice, homozygous for } \\
\text { N } f 2 \text {, exposed to asbestos fibers. }\end{array}$ \\
\hline $\begin{array}{l}\text { P16/CDKN2A and P15/CDKN2B: } \\
\text { frequent inactivation, mainly by } \\
\text { deletion. }\end{array}$ & $\begin{array}{l}\text { Cell cycle: loss of control of cell } \\
\text { proliferation at the G1-S transition. }\end{array}$ & $\begin{array}{l}\text { Asbestos: recurrent inactivation of the murine homologue p16/Cdkn2a is detected in mesothelioma } \\
\text { cells from asbestos-exposed mice. P19/Arf is also inactivated. }\end{array}$ \\
\hline
\end{tabular}


Table 2. Alteration in TSG in malignant mesothelioma [14]

\begin{tabular}{|c|c|c|c|c|c|c|c|}
\hline Gene & Epithelioid & Sarcomatoid & Biphasic & Type of mutation & Not specified & Method & Reference \\
\hline \multirow[t]{6}{*}{ NF2 } & $50 \%(13 / 26)$ & - & $22 \%(4 / 18)$ & Truncation form & - & Seq & Thurneysen et al. \\
\hline & $33 \%(10 / 30)$ & $40 \%(2 / 5)$ & $43 \%(3 / 7)$ & $\mathrm{HD}$ & - & FISH & Takeda et al. \\
\hline & - & - & - & $\begin{array}{l}\text { Mutation including } \\
\text { Hde }\end{array}$ & $56 \%(14 / 25)$ & Seq & Cheng et al. \\
\hline & - & - & - & $\begin{array}{c}\text { Mutation including } \\
\text { Hde }\end{array}$ & $50 \%(10 / 20)$ & Seq & Murakami et al. \\
\hline & - & - & $0 \%(0 / 1)$ & Mutation & $31 \%(8 / 26)$ & Seq & COSMIC \\
\hline & - & - & - & $\begin{array}{l}\text { Mutation (or } \\
\text { heterozygous D) }\end{array}$ & $\begin{array}{l}21 \%(53 \%) \\
{[11(28) / 53]}\end{array}$ & Seq & Bott et al. \\
\hline \multirow[t]{8}{*}{$\begin{array}{c}\text { CDKN2A } \\
\text { (p16INK4a/p14ARF) }\end{array}$} & $67 \%(20 / 30) c$ & $100 \%(3 / 3)$ & $100 \%(6 / 6)$ & $\mathrm{HDb}$ & - & Seq & Bott et al \\
\hline & $69 \%(49 / 71)$ & $100 \%(5 / 5)$ & $84 \%(16 / 19)$ & HD & - & FISH & Illei et al. \\
\hline & $56 \%(10 / 18)$ & $100 \%(22 / 22)$ & $88 \%(7 / 8)$ & HD & 一 & FISH & Wu et al. \\
\hline & $77 \%(23 / 30)$ & $100 \%(5 / 5)$ & $100 \%(7 / 7)$ & HD & - & FISH & Takeda et al. \\
\hline & - & - & - & HD & $67 \%(35 / 52)$ & FISH & Chiosea et al. \\
\hline & - & - & - & $\begin{array}{l}\text { HD (or heterozygous } \\
\text { D) }\end{array}$ & $\begin{array}{l}49 \%(42 \%) \\
{[16(14) / 33]}\end{array}$ & FISH & Onofre et al \\
\hline & - & - & - & $\begin{array}{l}\text { HD (or heterozygous } \\
\text { D) }\end{array}$ & $80 \%(20 \%)[12(3) / 15]$ & FISH & Matsumoto et al. \\
\hline & $42 \%(35 / 83)$ & $81 \%(22 / 27)$ & $44 \%(17 / 39)$ & Mutation & $57 \%(59 / 104)$ & Seq & COSMICd \\
\hline \multirow[t]{4}{*}{ BAP1 } & $21 \%(8 / 38)$ & $0 \%(0 / 5)$ & $40 \%(4 / 10)$ & Mutation & $18 \%(12 / 68)$ & Seq & Bott et al. \\
\hline & - & - & - & Mutatione & $24 \%(6 / 25)$ & Seq & Bott et al. \\
\hline & $81 \%(13 / 16)$ & $0 \%(0 / 2)$ & $20 \%(1 / 5)$ & Mutation & - & Seq & Yoshikawa et al. \\
\hline & $38 \%(26 / 68)$ & $0 \%(0 / 7)$ & $29 \%(6 / 21)$ & Mutation & $20 \%(19 / 93)$ & Seq & COSMIC \\
\hline
\end{tabular}

Table 3. Hallmarks of cancer comprises modulating factors and biological capabilities [15]

\begin{tabular}{|c|c|c|c|c|}
\hline Characteristic of cancer & Drug & Target & MOA & Clinical trial \\
\hline \multirow{2}{*}{ Activating invasion \& metastasis } & Tivantinib & Mesothelin & TKI c-MET & Phase I-II + cisplatin / pemetrexed \\
\hline & Amatuximab, SS1P & Mesothelin & Inhibitors of $\mathrm{HGF} / \mathrm{c}-\mathrm{MET}$ & $\begin{array}{l}\text { Single arm phase II first line + cisplatin / } \\
\text { pemetrexed }\end{array}$ \\
\hline \multirow{3}{*}{ Avoiding immune destruction } & Tremelimumab & CTL4 & Immune activating anti-CTL4 $\mathrm{mAb}$ & Single arm phase II \\
\hline & Lambrolizumab & PDL1 & Anti-PDL1 & ----- \\
\hline & Nivolumab & PD1 & Anti-PD1 & ----- \\
\hline Evading growth suppressors & ----- & RB1, TP53 & Cyclin-dependent kinase inhibitors & ----- \\
\hline Enabling replicative immortality & ----- & ----- & Telomerase inhibitors & ----- \\
\hline Inducing angiogenesis & Cediranib & VEGFR & Inhibitors of VEGF signaling & $\begin{array}{l}\text { Single arm phase II first line + cisplatin / } \\
\text { pemetrexed }\end{array}$ \\
\hline \multirow[t]{6}{*}{ Sustained proliferative signaling } & Gefitinib, Erlotinib & EGFR & EGFR inhibitors & Single arm phase II first line \\
\hline & Cetuximab & EGFR & MAb against EGFR & $\begin{array}{l}\text { Single arm phase II first line + platinum / } \\
\text { pemetrexed }\end{array}$ \\
\hline & Imatinib & PDGFR & MAb against PDGFR & $\begin{array}{l}\text { Single arm phase I first line + platinum / } \\
\text { pemetrexed }\end{array}$ \\
\hline & Dasatinib & PDGFR & MAb against PDGFR & Single arm phase II first line + gemcitabine \\
\hline & Cixutumumab & IGFR & MAb against IGFR & Single arm phase II in pretreated pts \\
\hline & Sorafenib, Sunitinib & $\begin{array}{l}\text { Multiple growth } \\
\text { factors }\end{array}$ & RTK & Single arm phase II in pretreated pts \\
\hline
\end{tabular}

Table 4. Non-FDA approved kinase inhibitor drugs [17-26]

\begin{tabular}{|c|c|c|c|}
\hline Drug & Clinical trial identifier number & Phase & Study design \\
\hline Vandetanib & NCT00597116 & Phase II & Randomized, Open Label, Efficacy Study \\
\hline Imatinibmesylate & NCT02303899 & Phase II & Efficacy Study, Open Label \\
\hline Defactinib & NCT01870609 & Phase II & Randomized, Efficacy Study, Double blind \\
\hline Tivantinib & NCT01861301 & Phase II & Open Label, Efficacy Study \\
\hline Gefitinib & NCT00787410 & FAK & Mese II \\
\hline Erlotinib & NCT00039182 & Non- Randomized, Open Label, Safety/Efficacy Study \\
\hline Dasatinib & NCT00652574 & Open Label, Safety/Efficacy Study \\
\hline Axitinib & NCT01211275 & Phase I & Open Label, Safety/Efficacy Study \\
\hline Alisertib & NCT02293005 & Phase I, II & Randomized, Open Label, Safety/Efficacy Study \\
\hline Trametinib & NCT01938443 & Phase II & Open Label, Safety/Efficacy Study \\
\hline & & Phase I & REG \\
\hline
\end{tabular}




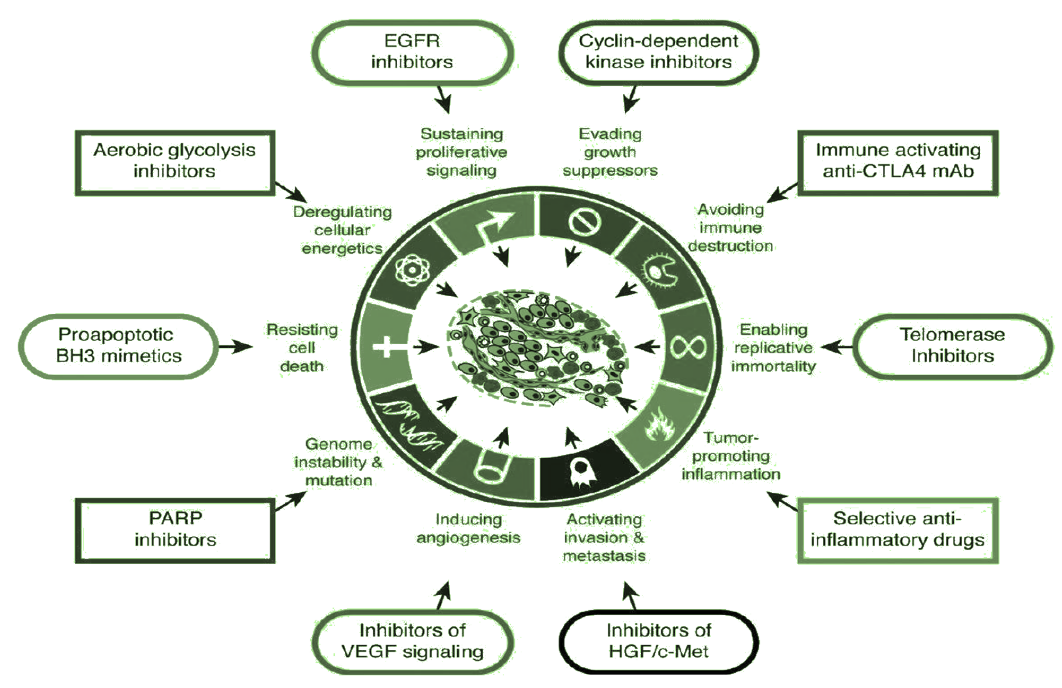

Figure 1. Hallmark of cancer with their targets [16]

Table 5. Non-FDA approved MAB drugs [27-31]

\begin{tabular}{|c|c|c|c|}
\hline Drug & $\begin{array}{c}\text { Clinical trial identifier } \\
\text { number }\end{array}$ & Phase & Study design \\
\hline Cetuximab & NCT00996567 & Phase II & Non-Randomized, Open Label, Efficacy Study \\
\hline Bevacizumab & NCT00407459 & Phase II & Non-Randomized, Open Label, Safety/Efficacy Study \\
\hline Tremelimumab & NCT01655888 & Phase II & Safety/Efficacy Study, Open Label \\
\hline Amatuximab & NCT02357147 & Phase II & Randomized, Double Blind, Safety/Efficacy Study \\
\hline BMS-986148 & NCT02341625 & Phase I, II & Non-Randomized, Open Label, Safety/Efficacy Study \\
\hline
\end{tabular}

Table 6. Non-FDA approved proteasome inhibitor drugs [32]

\begin{tabular}{|c|c|c|c|c|}
\hline Drug & Clinical trial identifier number & Phase & Study design \\
\hline Bortezomib & NCT00513877 & Phase II & Non-Randomized, Open Label & NF-kaapa B, Proteasome inhibitor \\
\hline
\end{tabular}

Table 7. Non-FDA approved vaccines [33-36]

\begin{tabular}{|c|c|c|c|}
\hline Vaccines & $\begin{array}{c}\text { Clinical trial identifier } \\
\text { number }\end{array}$ & Phase & Study design \\
\hline $\begin{array}{c}\text { WT-1 } \\
\text { analogue peptide vaccine }\end{array}$ & NCT01890980 & Phase II & Randomized, Double Blind, Safety/Efficacy Study \\
\hline TroVax & NCT01569919 & Phase II & Open Label, Safety/Efficacy Study \\
\hline H1299 Lysate Vaccine & NCT02054104 & Phase I, II & Randomized, Open Label, Efficacy Study \\
\hline K562 & NCT01143545 & Phase I & Safety Study, Open Label \\
\hline
\end{tabular}

Table 8. Non-FDA cytokine drugs [37]

\begin{tabular}{|c|c|c|c|}
\hline Drug & Clinical trial identifier number & Phase & Study design \\
\hline NGR-hTNF & NCT01358084 & Phase II & Randomized, Double Blind, Safety/Efficacy Study \\
\hline
\end{tabular}

Table 9. Non-FDA gene therapy [38]

\begin{tabular}{|c|c|c|c|c|}
\hline Drug & Clinical trial identifier number & Phase & Study design \\
\hline TargomiRs & NCT02369198 & Phase I & Open Label, Safety/Efficacy Study & EGFR \\
\hline
\end{tabular}

the restoration of expression of the miR-16 family. This leads to the downregulation of the expression of tumor-promoting genes and the inhibition of tumor cell growth. In addition, restoration of miR16 expression sensitizes the tumor cell to certain chemotherapeutic agents. miR-16, a family of micro RNAs, is critical to the regulation of gene expression and appears to have a tumor suppressor function; its expression is downregulated in various cancer cell types (Table 9).

\section{Conclusion}

The diagnosis of malignant pleural mesothelioma is a vital clinical challenge for physicians because the incidence of this aggressive tumor is growing. Though insufficient biopsy material so as to require perfect facts of invasion and lack of different typical morphologic features of malignancy with other cytological abnormalities that build perfect diagnosis of malignant pleural mesothelioma and to discover a novel and efficient diagnostic marker for malignant pleural mesothelioma, will be of enormous significance for its prognosis and treatment. During the last decade, various targeted agents have been explored in malignant pleural mesothelioma, and in some of them; the preclinical rationale was very weak for exploring clinical activity. Malignant pleural mesothelioma is characterized via a composite genomic modification, through the defeat of chromosomal loci encoding for 
different tumor suppressor genes such as TP53, NF2, p14, and p16. These types of genomic changes are very ordinary but, unluckily, these are not appropriate to be targeted through the available drugs. The deregulations in angiogenesis, apoptosis, and GFR pathway have been established, and these modifications may be agreeable to the intervention. Various clinical trials have tested different targeted agents focused against these pathways and receptors in order to inhibit the growth of mesothelial cell. There are some drugs which consistently revealed their activity in malignant pleural mesothelioma, but these drugs are under clinical trials.. The recent activities have increased our understanding of the tumor microenvironment, various immunotherapeutic modalities or combination therapy (like chemotherapy with immunotherapy). Additionally, the effects of such modalities in combination with immunotherapy in cancer patients are still exploratory phase. The complete perspective of immunotherapy treatment has not been realized and/or utilized. Proper preclinical and clinical designs are the important pillars in understanding the future of immunotherapy in treating cancer patients.

\section{References}

\section{Malignant Mesothelioma. National Cancer Institute.}

2. Delgermaa V, Takahashi K, Park EK, Le GV, Hara T, et al. (2011) Global mesothelioma deaths reported to the World Health Organization between 1994 and 2008. Bull World Health Organ 89: 716-724.

3. Price B, Ware A (2009) Time trend of mesothelioma incidence in the United States and projection of future cases: an update based on SEER data for 1973 through 2005. Crit Rev Toxicol 39: 576-588. [Crossref]

4. Sugarbaker DJ, Jaklitsch MT, Bueno R (2004) Prevention, early detection, and management of complications after 328 consecutive extra pleural pneumonectomies. J ThoracCardiovasc Surg 128: 138-146. [Crossref]

5. Bianchi C, Bianchi T (2007) Malignant mesothelioma: global incidence and relationship with asbestos. Industrial Health 45: 379-387. [Crossref]

6. Mesothelioma. Mesothelioma.com.

7. Wang NS (1996) Pleural mesothelioma: an approach to diagnostic problems. Respirology 1: 259-271. [Crossref]

8. Shigemitsu K, Sekido Y, Usami N (2001) Genetic alteration of the beta-catenin gene (CTNNB1) in human lung cancer and malignant mesothelioma and identification of a new 3p21.3 homozygous deletion. Oncogene 20: 4249-4257. [Crossref]

9. Murthy SS and Testa JR (1999) Asbestos, chromosomal deletions, and tumor suppressor gene alterations in human malignant mesothelioma. J Cell Physiol 180: 150-157. [Crossref]

10. Deguen B, Goutebroze L and Giovannini M (1998) Heterogeneity of mesothelioma cell lines as defined by altered genomic structure and expression of the NF2 gene. Int $J$ Cancer 77: 554-560. [Crossref]

11. De RienzoAandTesta JR (2000) Recent advances in the molecular analysis of human malignant mesothelioma. Clin. Ther 151: 433-438. [Crossref]

12. Lee YCG and Lane DP (2002) Cytokines in pleural diseases. In: Light RW, Lee YCG (eds). Pleural Disease, an International Textbook. Arnold Publishers 63-89.

13. Marzo AL, Fitzpatrick DR, Robinson BW, Scott B (1997) Anti-sense oligonucleotides specific for transforming growth factor beta2 inhibit the growth of malignant mesothelioma both in vitro and in vivo. Cancer Res 57: 3200-3207. [Crossref]

14. Sekido Y (2013) Molecular pathogenesis of malignant mesothelioma. Carcinogenesis 34: 1413-1419. [Crossref]

15. Hanahan D, Weinberg RA (2011) Hallmarks of cancer: the next generation. Cell 144: 646-674. [Crossref]

16. HiddingaBI, Rolfo, C, Van Meerbeeck JP (2014) Mesothelioma treatment: are we on target? A review. Journal of Advanced Research 1-35. [Crossref]

17. AstraZeneca; AstraZeneca. An Efficacy and Safety Study with Vandetanib to Treat Inoperable or Relapsed Malignant Mesothelioma. In: ClinicalTrials.gov. Bethesda (MD): National Library of Medicine (US).
18. IstitutoClinicoHumanitas; IstitutoClinicoHumanitas. Combination of Gemcitabine and ImatinibMesylate in Pemetrexed-pretreated Patients with Pleural Mesothelioma. In: ClinicalTrials.gov. Bethesda (MD): National Library of Medicine (US).

19. Verastem, Inc.; Verastem, Inc.Placebo Controlled Study of VS-6063 in Subjects with Malignant Pleural Mesothelioma (COMMAND). In: ClinicalTrials.gov. Bethesda (MD): National Library of Medicine (US).

20. National Cancer Institute (NCI); National Cancer Institute (NCI). Tivantinib in Treating Patients with Previously Treated Malignant Mesothelioma. In: ClinicalTrials. gov. Bethesda (MD): National Library of Medicine (US).

21. AstraZeneca; AstraZeneca. An Open-label, Phase II Trial of ZD1839 (IRESSA) in Patients with Malignant Mesothelioma. In: ClinicalTrials.gov. Bethesda (MD): National Library of Medicine (US).

22. National Cancer Institute (NCI); National Cancer Institute (NCI). Erlotinib in Treating Patients with Malignant Mesothelioma of the Lung. In: ClinicalTrials.gov. Bethesda (MD): National Library of Medicine (US).

23. M.D. Anderson Cancer Center; M.D. Anderson Cancer Center. Dasatinib in Resectable Malignant Pleural Mesothelioma. In: ClinicalTrials.gov [Internet]. Bethesda (MD): National Library of Medicine (US).

24. The Netherlands Cancer Institute; The Netherlands Cancer Institute. Axitinib in Malignant Mesothelioma (N08CPA). In: ClinicalTrials.gov. Bethesda (MD): National Library of Medicine (US).

25. M.D. Anderson Cancer Center; M.D. Anderson Cancer Center. Alisertib in Malignant Mesothelioma. In: ClinicalTrials.gov. Bethesda (MD): National Library of Medicine (US).

26. GlaxoSmithKline; GlaxoSmithKline. A Dose Escalation Study to Assess Safety of GSK2256098 (FAK Inhibitor) in Combination with Trametinib (MEK Inhibitor) in Subjects with Advanced Solid Tumors. In: ClinicalTrials.gov. Bethesda (MD): National Library of Medicine (US).

27. University Hospital, Ghent; University Hospital, Ghent. A Study of Cetuximab Combined with Cisplatin or Carboplatin/Pemetrexed as First Line Treatment in Patients with Malignant Pleural Mesothelioma. (MesoMab). In: ClinicalTrials.gov. Bethesda (MD): National Library of Medicine (US).

28. IstitutoClinicoHumanitas. Phase II Study of Bevacizumab, Pemetrexed and Carboplatin as First-Line Therapy in Malignant Pleural Mesothelioma. In: ClinicalTrials.gov. Bethesda (MD): National Library of Medicine (US).

29. AziendaOspedalieraUniversitariaSenese;

Michele Maio, AziendaOspedalieraUniversitariaSenese. The Anti-CTLA-4 Monoclonal Antibody Tremelimumab in Malignant Mesothelioma. In: ClinicalTrials.gov. Bethesda (MD): National Library of Medicine (US).

30. Morphotek; Morphotek. Study of the safety and efficacy of amatuximab in combination with pemetrexed and cisplatin in subjects with unresectable malignant pleural mesothelioma (MPM). In: ClinicalTrials.gov. Bethesda (MD): National Library of Medicine (US).

31. Bristol-Myers Squibb; Bristol-Myers Squibb. A Phase I/IIa Study of BMS-986148 in Subjects with Select Advanced Solid Tumors. In: ClinicalTrials.gov. Bethesda (MD): National Library of Medicine (US).

32. ICORG- All Ireland Cooperative Oncology Research Group; ICORG- All Ireland Cooperative Oncology Research Group. Bortezomib in Treating Patients with Malignant Pleural Mesothelioma. In: ClinicalTrials.gov. Bethesda (MD): National Library of Medicine (US).

33. M.D. Anderson Cancer Center; M.D. Anderson Cancer Center. Phase II Study of Adjuvant WT-1 Analog Peptide Vaccine in MPM Patients after MSK10-134. In: ClinicalTrials.gov. Bethesda (MD): National Library of Medicine (US).

34. Wales Cancer Trials Unit; Wales Cancer Trials Unit. A Phase II Trial to Assess TroVax ${ }^{\circledR}$ Plus Chemotherapy in Patients with Malignant Pleural Mesothelioma (SKOPOS). In: ClinicalTrials.gov. Bethesda (MD): National Library of Medicine (US).

35. National Cancer Institute (NCI); National Institutes of Health Clinical Center (CC) (National Cancer Institute (NCI)). Adjuvant Tumor Lysate Vaccine and Iscomatrix With or Without Metronomic Oral Cyclophosphamide and Celecoxib in Patients with Malignancies Involving Lungs, Esophagus, Pleura, or Mediastinum. In: ClinicalTrials. gov. Bethesda (MD): National Library of Medicine (US).

36. National Cancer Institute (NCI); National Institutes of Health Clinical Center (CC) (National Cancer Institute (NCI)). Pilot Study of Allogeneic Tumor Cell Vaccine with Metronomic Oral Cyclophosphamide and Celecoxib in Patients Undergoing Resection of Lung and Esophageal Cancers, Thymic Neoplasms, and Malignant Pleural Mesotheliomas. In: ClinicalTrials.gov. Bethesda (MD): National Library of Medicine (US). 
37. MolMedS.p.A; MolMedS.p.A.Phase II Study of NGR-hTNF Versus Placebo as Maintenance Treatment in Patients with Advanced Malignant Pleural Mesothelioma (NGR019). In: ClinicalTrials.gov. Bethesda (MD): National Library of Medicine (US).
38. University of Sydney; University of Sydney. MesomiR 1: A Phase I Study of TargomiRs as 2nd or 3rd Line Treatment for Patients with Recurrent MPM and NSCLC. In: ClinicalTrials.gov. Bethesda (MD): National Library of Medicine (US).

Copyright: (O2019 Allen T. This is an open-access article distributed under the terms of the Creative Commons Attribution License, which permits unrestricted use, distribution, and reproduction in any medium, provided the original author and source are credited. 